\title{
Children and Adolescents' Affect during Lock-down for Covid-19: Case of Pakistan
}

\section{Abstract}

The current study has investigated 10-18-year-old Pakistani students' affect during the lock-down due to Covid-19. The data were initially gathered through semi-structured interviews of the nine students. The interview data were analyzed to develop a 'Lockdown Affect Scale'. The quantitative data were collected online from May 10, 2020, to May 25, 2020. Overall 189 students registered their responses. The data analysis indicates that students of 10-18 year old are experiencing 'negative affect' during the lock-down. Moreover, the students who claimed to be independent learners had higher 'positive affect' as compared to those who claimed not to be independent learners. The analysis further indicated that boys had a higher 'positive affect' as compared to girls during the lock-down. The findings suggest the inclusion of disaster and risk education in schools. The findings further indicate a need for promoting selfregulatory learning among the students to help them cope with the unprecedented situations positively.

Keywords: Lock-down, Covid-19, Well-being, Negative Affect, Positive Affect, Independent learning

\section{Introduction}

Covid-19 has impacted people of all ages in different ways. Some have fallen victims to the disease while others are suffering economically, politically, socially or psychologically. Youth and children are no exception. A large number of children and youth are suffering mentally because of the closure of schools and universities. According to UNESCO (2020 a), approximately 1.2 billion students and youth across the planet are affected by school and university closures due to the Covid-19 outbreak. One of the consequences of this closure is deprivation in terms of social interaction. UNESCO (2020 b) also believes that "schools are hubs of social activity and human interaction. When schools close, many children and youth 
miss out of on social contact" (UNESCO, 2020). Giannini (2020) reports the findings of a recent survey of 6,771 students in Thailand. The survey found out that "more than 7 in 10 children and young people said the pandemic is affecting their mental health, causing stress, worry and anxiety". Tiwari et al. (2020) argue that enhanced restrictions (movement, activity, play etc.) and reduced social interactions (friends, peers, neighbours etc.) have led to negative emotional environment in the family and community. In addition, it has replaced positive emotions among 9-11-year-old children with sadness, quarrelling behaviour, aggression, disturbed routine and boredom. Đapić, Flander and Prijatelj (2020) reviewed 24 published studies on Covid-19 and found a range of negative psychological effects caused by Covid-19. Kapasia et al. (2020) also reported depression and anxiety among the undergraduate students of India due to lock-down.

Lee (2020) argues that school closures as a social distancing measure can result in social isolation if the children are living in an abusive home. According to UNICEF (2020), closing schools during the Ebola virus epidemic in Africa from 2014-2016 resulted in higher children's neglect and sexual abuse. Lee and Ward (2020) conducted a survey after 2 weeks of lock-down in the US. They found that most parents became closer to their children. However, many other parents reported high levels of psychological and physical punishment of children. About $20 \%$ parents mentioned that they had spanked or slapped their child or children at least once in the past two weeks. Similarly, the rates of yelling and screaming at children were high in the lock-down period. Lee (2020) mentions the report that indicates a three times increase in violence during the lock-down in February.

Though literature indicates increased rates of child abuse, neglect, and exploitation during previous public health emergencies like the Ebola epidemic, there less known about the long-term mental health effects of large-scale disease outbreaks on children and adolescents (Lee, 2020). It is also important to note that researchers have studied children's psychological well-being in a variety of contexts and circumstances e.g., in disaster and 
emergencies (Balaban, 2006); homelessness (Downer, 2013); refugees (Badri, Eltayeb, Mohamed, \& Verdeli, 2020; McFarlane et al, 2011); international parental migration or immigration (Mazzucato et al., 2015; Perreira \& Ornelas, 2011); war (Betancourt \& Khan, 2008; Machel, 2001; Veronese et al., 2017); and detention (DeFosset, Schooley, Abrams, Kuo, \& Gase, 2017). There is a need to monitor and study "how prolonged school closures, strict social distancing measures, and the pandemic itself affect the well-being of children and adolescents" (Lee, 2020). The current study was an attempt to explore the well-being/ affect of the children and adolescents during Covid-19 lock-down situation in Pakistan. In addition, the study has tried to understand the 'affect' under the lock-down in terms of students' gender, their age and their 'self-regulation' or 'independent learning' attitudes. The study adds to the existing literature on the impact of lock-down for Covid-19 on children and adolescents in terms of their well-being. In addition, the study contributes to the literature on 'affect scales'. The researchers developed "Lock-down Affect Scale” for this study to measure students' affect under the lock-down situation.

The specific research questions addressed in the current study were:

1. How has Covid-19 impacted the well-being/affect among 10-18 year old Pakistani students?

2. How did the attitude of independent learning during the lock-down influence the well-being/ affect among 10-18 year old Pakistani students?

3. Do gender and age of students predict well-being/ affect among 10-18 years old students during the lock-down?

4. How did engagement in activities during the pandemic influence the wellbeing/affect among 10-18 year old Pakistani students? 
In the current study, well-being and affect have been used interchangeably. Following Whitebread et al. (2009), the current study has also used the term independent learning synonymously with self-regulated learning or self-regulation. 


\section{Study Hypotheses}

Conversant with the question 1-3, following null hypotheses were developed.

Null Hypothesis 1: The mean scores of the 10-18 years students on the well-being scale is equal to the hypothetical mean value of 3 .

Null Hypothesis 2: There is no difference in the mean scores of the two groups of students (independent learners and not independent learners) on the scale of 'affect'.

Null Hypothesis 3: There is no difference in the mean scores of the female and male students on the scale of 'affect'.

Null Hypothesis 4: There is no difference in the mean scores of the 10-12 year, 13-14 year, 15-16 year, and 17-18 year old students on the 'Lock-down Affect Scale'.

\section{Study Framework}

The study framework was built around the concepts of well-being, affect (positive and negative), independent learning and self-regulation.

\subsection{Well-being and Affect}

The concept of well-being is contentious. Scholars have classified well-being in two broader categories: subjective well-being and psychological well-being. Subjective well-being is delineated in terms of positive and negative 'affect' while psychological well-being refers to self-referent attitudes of mastery and self-acceptance (Burns \& Machin, 2013). Pollard and Lee (2003) found inconsistencies and variation in the understanding of the concept. In literature, child well-being has been described in terms of happiness or self-esteem, standard of living, or absence of well-being i.e. depression (Pollard \& Lee, 2003). Çardak (2013) believes that psychological well-being is concerned with an individual's construction of thoughts in order to feel happy, whereas subjective well-being refers to individual's delight or 
happiness in life. The subjective well-being focuses on those experiences that make life either enjoyable or unpleasant (Burns \& Machin, 2013).

\section{Affect}

Affect refers to diffuse positive or negative mood states or trait dispositional tendencies to experience positive or negative feelings (Elfenbein 2007). Affect has been classified into two categories: positive and negative affect. Scholars have described negative and positive affect in terms of moods, feelings, traits and symptoms. van Knippenberg et al. (2010) view negative affect as "the extent to which one experiences negative feelings and moods (i.e., distress, nervousness, hostility), and trait negative affect accordingly refers to the disposition to experience such states" (p. 734). Singh and Jha (2008) describe positive affect as "the extent to which an individual experiences positive emotional states such as joy, interest, confidence and alertness". Negative Affect refers to the extent to which an individual experiences negative emotional states such as fear, sadness, anger, guilt, contempt and disgust (Snyder \& Lopez, 2002 cited in Singh \& Jha, 2008). Watson et al. (1988) identify positive affect as a pleasurable engagement with one's environment (i.e., being enthusiastic, alert, active). They view negative affect as the unpleasant engagement (i.e., being angry, upset, fearful) with one's environment. Burke et al. (2010) describe negative affect in terms of symptoms of touchy, angry, and spiteful.

\subsection{Predictors of Well-being/ Affect}

Literature shows that children's well-being varies with age. For example, Greene (1990) found that positive affect among the elementary school was higher than older students. Similarly, Chang et al. (2003) reported higher life satisfaction in grade II children as compared to grade VIII children. Researchers have also found that personality is a predictor of subjective well-being of adolescents and adults (Fogle et al.,2002; Lyubomirsky et al., 2005). People who are self-promoting show higher levels of satisfaction and happiness. They 
take stressful life events in a lesser negative way (Lyubomirsky \& Ross, 1999). Researchers have also noticed a relationship between the attitude of openness and 'affect'. Kling et al. (2003) found that the attitude of openness to any experience increases positive affect. Similarly, Headey and Wearing (1989) found that openness is correlated with positive and negative affect.

Gender and learning activities have been identified as the predictors of affect among the children and adolescents. Burns and Machin (2013) found that females scored higher on negative affect. Similar results were found in the studies that included adolescents. For example, Garcia (2011) and Jaques and Mash (2004) noticed a higher negative affect among girls. van der Laan and Eichelsheim (2013) found in their study with detained children that structured daily activities related positively to autonomy and well-being, and negatively to aggressive conduct. In addition, some juveniles mentioned that school or recreational activities reduce boredom, decrease worrying thoughts and bring a positive atmosphere to the group.

\subsection{Independent Learning or Self-regulated Learning}

The concept of 'independent learning' has been described differently in literature. Meyer (2010) argues that "the concept of 'independent learning' is associated with, or part of, a number of other educational concepts and wider policy agenda of contemporary relevance such as 'personalised learning' and 'ownership' of learning”' (p.1). Whitebread et al. (2009) used the term 'independent learning' synonymously with 'self-regulated learning'. Metacognition is another term that has been mentioned in literature in relation to independent and self-regulated learning (Lai, 2011). Metacognition refers to thinking about thinking (Flavell, 1979). In other words, it refers to "the knowledge and control children have over their own thinking and learning activities" (Cross \& Paris, 1988, p. 131). Schraw (1998) believes that metacognition is not domain-specific. Instead it is a multidimensional set of 
general skills. Like metacognition, independent learning and self-regulated also focus on selfcontrol, motivation and responsibility (Meyer, 2010).

Self-regulation is the key element of all the related constructs i.e. independent learning, metacognition and self-directed learning. Self-regulation is a process by which individuals exercise their agency (Bandura, 2001) and develop their autonomy (Leaver et al., 2003). Personal control and agency are the key sources of intrinsic motivation for independent or self-regulatory learning (Zimmerman, 1995). Self-regulated learners are persistent, motivated and manage their time effectively (Pintrich et al., 1993). They set targets and engage in strategies to reach the set targets.

Self-regulatory learning is important for a number of reasons. Dettori and Persico (2011) argue that the people who have the capacity to learn independently are more likely to be successful than those who do not have these characteristics. Bronson (2000) contends that the development of self-regulation or metacognitive processes is fundamental to young children's psychological growth. She further argues that self-regulation affects the emotional, cognitive, prosocial, and motivational developments throughout the different phases of early childhood. Ponitz et al. (2008) reviewed literature and found a connection between young children's self-regulation with effective classroom behaviour and high academic achievement. They further identified poor self-regulation as a predictor of future problems in school.

Considering the key impact of self-regulatory learning, scholars recommend the schools to help children become self-regulatory learners in their early years of schooling (Whitebread et al., 2005). Literature shows that children can learn self-regulation, and take responsibility and ownership of their learning by being involved in the processes of 'selfassessment' (Black \& Wiliam,1998), making choices, and taking decisions (Whitebread et al., 2005). Children persistently work to achieve their set targets if they get the opportunity to make their own choices and decisions (Whitebread et al., 2005). In addition, the researchers 
are trying to find a relationship between blended learning, online learning and self-regulatory learning (Broadbent, 2017; Broadbent \& Poon, 2015).

\section{Study Context}

Starting from Wuhan, China in 2019, the novel coronavirus disease (Covid-19) reached other parts of the world at the start of the year 2020. It reached Pakistan in the month of February. Two cases of Covid-19 were reported by February 27, 2020. Covid-19 was declared a 'pandemic' on March 11, 2020 by the World Health Organization (WHO, 2020). Like other countries, Pakistan imposed complete lock-down in the country in the month of March as an attempt to curb the spread of Covid-19. All educational institutes of the country were closed on March 16, 2020. Initially, the schools and universities were closed until May 31, 2020. The closure has been extended until July 15, 2020. It is expected that the schools will not open after July 15, 2020 as there are still more than 100,000 active Covid-19 patients in the country and the number is constantly increasing. Until July 7, 2020, there are more than 235,000 reported cases of Covid-19 in Pakistan.

Due to the sudden closure of schools on March 16, 2020 in Pakistan, most of the schools were not ready for online classes. Most of the schools had not started online classes at the time when the current study was conducted (May 10-May 25, 2020). Most of the schools were using Google Classroom and WhatsApp as a medium of assigning tasks to the students. Some schools were holding online sessions through Google Hangout, Google Meet, Skype and Zoom. It is also important to note that disaster and risk education is not a part of school curricula in Pakistan.

\section{Study Methods and Materials}

The researchers employed a mixed method approach to study the impact of lock-down on 1018 year old students in Pakistan. 


\subsection{Subjects}

Nine students (five girls and four boys) participated in the qualitative phase of the study. For the quantitative phase, 189 students participated in the study. Age-wise number of the students is as follows: 28 students of age 10-12; 76 students of age 13-14 years; 38 students of 15-16 years; and 42 students of 17-18 years. Five students did not mention their age. The survey was conducted online, so only those students participated in the study who had an access to the internet and an electronic device (e.g. smartphone, laptop or tablet).

\subsection{Instrumentation}

The study employed two instruments to collect data. They were: semi-structured, short interviews, and a questionnaire. The basic purpose of the interviews was to develop a scale (in the light of students' responses) to measure 10-18 year old students' affect during lockdown to curb Covid-19. Though the researchers (e.g. Ebesutani et al., 2012; Huebner \& Dew, 1995; Laurent et al., 1999) have developed and used different scales to measure the positive and negative affect among children, these scales were not used in the current study because Covid-19 was a new phenomenon. Therefore, the researchers decided to develop a scale in the light of students' interview responses.

\subsubsection{Interview}

The researchers developed a short, semi-structured interview protocol in the light of the study framework. The protocol was pilot tested with two students to know about the relevance of questions. After the pilot testing, an additional open-ended question "any other thought that you want to share" was included in the interview protocol (annexure 1).

\subsubsection{Questionnaire}

On the basis of data interpretation of the interviews, a questionnaire was developed. The questionnaire had nine Likert scale items (based on feelings), one yes/ no question (related to quarrelsome behaviour) and three short questions. The instrument was pilot tested with 28 
students to determine its reliability. Cronbach alpha value of the questionnaire was found 0.76. Conventionally, Cronbach alpha value of 0.7 or above is considered acceptable to use an instrument.

\subsection{Study Procedure}

1. Initially, nine students (five female and four male) of age 10-17 were interviewed through video call to know about their wellbeing/ affect during the lockdown for Covid-19 and the activities they were engaged in. The interviewees were not interrupted in between. No leading question was asked. However, some prompts like "can you give an example" or "why" or "how" were used.

2. An online questionnaire (Google Form) was developed in the light of the interview responses.

3. The questionnaire was pilot tested with 28 students. Reliability of the Likert sacle items was checked through Cronbach alpha values. Six students did not answer one short question. Four students repeated what they had written in response to another questions. That question was removed from the final questionnaire (annexure 2).

4. The link of the questionnaire was shared with the students through WhatsApp, Instagram, and email.

5. Students registered their responses online through Google Forms.

6. The excel sheet from the google form was downloaded for analysis.

\subsection{Data Analysis}

The interview data were coded through open-coding. The researchers read the interview transcripts separately, coded the data, and then compared their codes to reach consensus. The quantitative data were analysed through percentages, t-test and ANOVA. Items 1-8 were based on negative feeling. The following key was used to code the data for items 1-8.

Very Often $=1 ;$ Often $=4 ;$ Sometimes $=3 ;$ Rarely $=2 ;$ Never $=1$ 
Item 9 was related to positive feeling. A reverse key was used to code the data for item 9.

A cut off value of ' 3 ' was decided as a 'positive affect' during lock-down. It was assumed that a mean score of ' 3 ' or above will depict a positive affect.

\subsection{Ethical Considerations}

Although study involved human participants, the study did not require permission of ethics committee of the university because there was no risk of psychological or physical harm or stress to the study participants. Participation in the current study was completely voluntary and anonymous. Participants were not required to share their emails or any other personal information. The purpose of the study was shared with them. In qualitative interviews, parents' permission was taken. Parents were asked to sit with their children (during the interview) if they desired so. Children were allowed to leave the interview without telling any reasons. In addition, they were free to respond or not to a question.

\section{Results}

Results have been organized under two headings: Findings from the Interview Data; and Findings from Questionnaire Data.

\subsection{Findings from the Interview Data}

The results of the interview data have been presented under three themes.

\subsubsection{Feelings}

Interview data showed that the children of age 10-17 were experiencing following feelings during the lock-down:

1. Sadness

2. Laziness 


\section{Helplessness}

4. Anger, Irritation

5. Feeling lost

6. Frustration

7. Boredom

8. Feeling relaxed

9. Feeling of being imprisoned

The feeling of boredom was the strongest among the respondents. Six out of nine students said that they were feeling extremely bored. One student mentioned:

I complete my work assigned by the teachers on Google Classroom. It takes me 2-3 hours daily. After completing the work I am completely free. I do not know what to do after that.

Another student:

I feel bored mostly. I have started learning guitar through Youtube tutorials. It is good.

Three students said that the most prevalent feeling in them was of helplessness. One student (12 year old) mentioned:

I feel I am in jail. I feel helpless. Though I am getting very good food and have access to TV and internet but I still feel that I am in jail and helpless.

One student said that:

I have strong bad feeling about my spoiled routine of going to bed late and getting up late in the morning. I feel frustrated sometimes when I get up late or go to bed late. I do not like this but I am carrying on with this. 
One student said that due to the lock-down he felt sad and lost consistently. Three students maintained that they were fine with the lock-down. One of them said:

I am quite relaxed and happy as she was following her own routine. There was no rush of getting up early morning and going to school or doing homework.

\subsubsection{Self-regulation}

The data indicated that some students were showing self-regulation. Four students mentioned that they were engaged in some sort of activities during the lock-down. One of them said:

I have started helping my mother in cooking. It is cool. I am learning this new skill. It is good.

Another student mentioned:

I find enough time for painting. That is very good. During school days, I could not focus on my Art. It is an opportunity for me to do what I really want to do.

Another student said:

I am reading my favourite books. I have time and I am using it for reading. I am planning to write something too.

Above responses indicated that some students were engaged in self-regulation and they were finding it good.

\subsubsection{Change in Behaviour}

Four students mentioned a change in their behaviours. Three students said that they had started spending time with their family. One of them said:

I am spending more quality time with my family. Sometimes there are fights. But mostly I am enjoying with them. 
Two students mentioned that they had become quarrelsome and short-tempered. One of them mentioned:

I have started fighting with my sister so often. This is not good. I know. But I am unable to help myself. I get annoyed easily.

\subsection{Findings from the Questionnaire Data}

The quantitative data have been analysed in terms of descriptive statistics and inferential statistics. Reliability of the final data has been presented in the Table 1.

Table 1: $\quad$ Cronbach Alpha Value of the Final Data

\begin{tabular}{llcc}
\hline & Age group & No. of Responses & $\begin{array}{c}\text { Cronbach Alpha } \\
\text { Value }\end{array}$ \\
\hline 1 & $10-12$ Years & 28 & 0.81 \\
2 & $13-14$ Years & 78 & 0.88 \\
3 & $15-16$ Years & 40 & 0.83 \\
4 & $16-18$ Years & 41 & 0.896 \\
\hline
\end{tabular}

\subsubsection{Overall Percentages}

Mean scores of 134 (71\%) students were found less than ' 3 ' (cut off value for positive affect) on the 9 items of the 'Covid-19 Affect Scale'. Moreover, the data showed lowest scores on the item 4 and 5 (related to feelings of boredom and laziness). This indicates that the feelings of boredom and laziness were the most frequent feelings among the students of 10-18 year age. In response to the question "Have you started fighting with your siblings more often?", 44\% students (83/ 189) said they had started fighting more; $39 \%$ students (73/189) said that they were not fighting whereas $17 \%(33 / 189)$ mentioned that they did not know if they were 
fighting more with their siblings. The figures indicate that lock-down situation had led to more quarrelsome behaviours amongst the students of age 10-18 years.

Mean scores on the 9 individual items of the 'Covid-19 affect scale' have been shown in Figure 1. The scores show that the students scored maximum on item 9 i.e. is about feeling relaxed. This shows that despite of many negative feelings like sadness, laziness, feeling lost, and boredom, majority of the students felt relaxed during lock-down. The lowest scores (Figure 1) were observed on the item related to feeling lazy and bored.

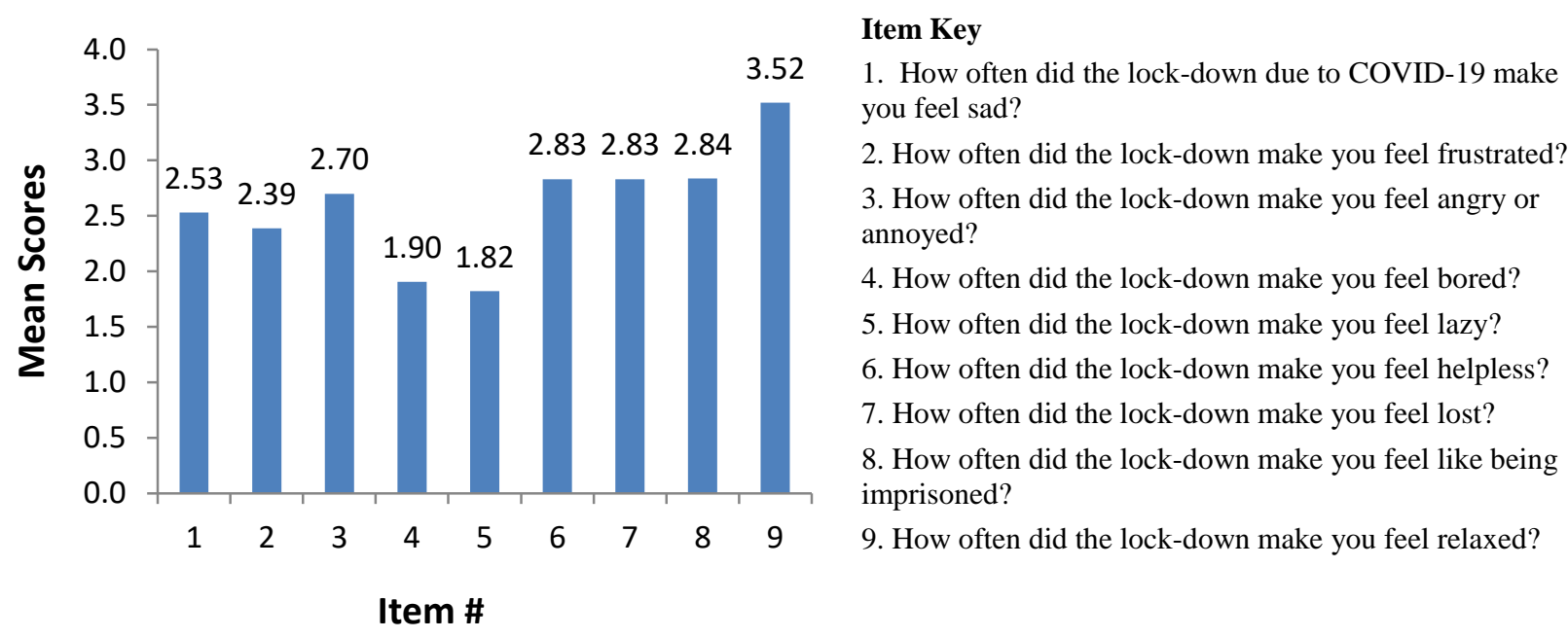

Figure 1: Mean Scores on the 9-Item Affect Scale

The data were analyzed to find the percentage of the students who reported themselves as independent learners (as a result of lock-down or they were already independent before the lock-down) and those who did not. The data indicated that $43 \%$ students (82/ 189) reported themselves as independent learners; 32\% (60/189) reported themselves as 'Not independent learners'; while $25 \%$ did not respond or were not aware if they were independent learners or not. The data was further analysed to find age-wise variation in responses regarding 'selfreported independent learners'. The findings have been mentioned in the Table 2. 
Table 2: $\quad$ Self-Reported Independent Learners

\begin{tabular}{llccc}
\hline & Age group & Total No. of Students & $\begin{array}{c}\text { No. of Students who } \\
\text { claimed to be }\end{array}$ & Percentage \\
& & & Independent Learners \\
& & 28 & 12 & $43 \%$ \\
\hline 1 & $10-12$ Years & 76 & 44 & $58 \%$ \\
3 & $13-14$ Years & 38 & 17 & $45 \%$ \\
4 & $16-16$ Years & 42 & 19 & $45 \%$ \\
\hline
\end{tabular}

* 5 students did not mention their age

The data analysis indicates that more than $50 \%$ of the 13-14 year old age group claimed to have become more independent learners during lock-down or they had already been independent. Relatively, a lesser number of students of other age groups claimed to have become independent learners.

\subsubsection{Aggressive Behaviour of Self-reported Independent Learners vs Not Independent Learners}

The data indicated that $38 \%$ ( 31 out of 82 students who claimed to be independent learners) had started fighting with their siblings. On the other hand, $48 \%$ (29 out of 60 students who claimed NOT to being independent learners) had started fighting with their siblings. This indicates a difference in the aggressive behaviour of the two groups.

\subsubsection{Testing of Null Hypothesis 1}

To test the hypothesis 1 "The mean scores of the 10-18 year-old students on the well-being scale is equal to the hypothetical mean value of 3", one sample t-test was employed. The data analysis indicated that the mean scores of the 10-18 year old children were ' 2.59 ' with a standard deviation of 0.8 . The result of the one sample t-test is as follows. 


$$
t(188)=6.9337, p<.0001
$$

The t-test result indicates that the well-being of the 10-18 year-old students is significantly low during the lock-down.

\subsubsection{Testing of Null Hypothesis 2:}

To test the hypothesis 2 "there is no difference in the mean scores of the two groups of students (independent learners and 'not' independent learners) on the scale of affect", independent sample t-test was employed. The data analysis indicated that the mean scores of the students who claimed to be independent learners were '2.69' with a standard deviation of 0.76. The mean scores of the students who claimed not to be independent thinkers was ' 2.37 ' with a standard deviation of ' 0.79 '

$$
t(141)=2.4795, p<.05
$$

The null hypothesis 2 could not be rejected leading to a conclusion that the students who claimed to be independent learners had a lower negative affect as compared to the students who claimed that they were not independent thinkers.

Forty-six students did not mention if they were independent learners or not.

\subsubsection{Testing of Null Hypothesis 3:}

To test the hypothesis 3 "there is no difference in the mean scores of the female and male students on the scale of affect", independent sample t-test was employed. The data analysis indicated that the mean scores of the female students was ' 2.54 ' with a standard deviation of 0.78 . The mean scores of the male students was ' 2.92 ' with a standard deviation of ' 0.89 '

$$
t(183)=2.19, p<.05
$$


The null hypothesis 3 could not be rejected leading to a conclusion that the male students had a lower negative affect as compared to the female students. Scores of four students were not included in the test as they did not mention their age.

\subsubsection{Testing of Null Hypothesis 4:}

To test the null hypothesis 4 "there is no difference in the mean scores of the 10-12 year, 1314 year, 15-16 year, and 17-18 year old students on the Lock-down Affect Scale”, ANOVA was run. The results indicated that no group differed from each other on the basis of their age. The mean scores of the four groups have been shown in the Table 2 .

Table 3: Results of ANOVA Test

\begin{tabular}{lll}
\hline & Age group & Mean Score \\
\hline 1 & $10-12$ Years & 2.77 \\
2 & $13-14$ Years & 2.61 \\
3 & $15-16$ Years & 2.53 \\
4 & $16-18$ Years & 2.47 \\
\hline
\end{tabular}

\subsubsection{Lock-down as an Opportunity}

Majority of the students - 74\% (140/189) - found the lock-down as an opportunity to do something they were unable to do frequently before the lock-down. Ninety-four students out of 140 named the action or activity they were engaged in during lock-down. Frequencies of the activities have been presented in the table 4 . 
Table 4: Frequency of Actions or Activities done by the Students during the Lock-

down

\begin{tabular}{|c|c|c|}
\hline & Activity & Frequency \\
\hline 1 & Spending time with the family & 18 \\
\hline 2 & Reading Books & 17 \\
\hline 3 & Cooking and Baking & 17 \\
\hline 4 & Art work & 8 \\
\hline 5 & Online internships & 5 \\
\hline 6 & Exploring new things, hobbies and talents & 5 \\
\hline 7 & Writing & 4 \\
\hline 8 & Language learning or practising & 4 \\
\hline 9 & Reading the Holy Book: The Quran & 4 \\
\hline 10 & Self-reflection & 3 \\
\hline 11 & Watching movies and TV shows & 3 \\
\hline 12 & Playing physical games & 2 \\
\hline 13 & Studying more & 2 \\
\hline 14 & Physical Exercise & 1 \\
\hline \multirow[t]{2}{*}{15} & Gaming & 1 \\
\hline & Total & 94 \\
\hline
\end{tabular}

Further analysis indicated that 23 students $(38 \%$ of the 60 students who reported themselves as 'not' independent learners) took the lock-down as an opportunity to do something they were not able to do frequently before. On the other hand 77 students ( $94 \%$ of the 82 students who reported themselves as independent learners) took the lock-down as an opportunity to do something they were not able to do frequently before. 


\section{Discussion}

The study findings have been discussed in the light of the study context and prior literature on Covid-19 and children's or adolescents' well-being. The findings have also been discussed in the light of literature on self-regulatory/ independent learning.

Mean scores of 134 (71\%) students were less than 3 (hypothetical cut off value for positive affect) on the '9-Item Covid-19 affect scale'. This percentage is comparable with the percentage of students (70\%) in Thailand who mentioned that the pandemic was affecting their mental health, causing stress, worry and anxiety (Giannini, 2020). Similarly, the findings of lowest affect scores on item 4 and 5 (related to feelings of boredom and laziness) and that $44 \%$ students $(83 / 189)$ claimed that they had started quarrelling and fighting more with their siblings is in line with Tiwari et al. (2020) who argues that enhanced restrictions (movement, activity, play etc.) and reduced social interactions had replaced positive emotions among 9-11-year-old children with sadness, quarrelling behaviours, aggression, disturbed routine and boredom. The findings show that the students in Pakistan are also experiencing negative affect like students in other parts of the world. This shows that Covid-19 is psychologically impacting students all over the world. It is also interesting to note that along with a range of negative feelings, students' are relatively more relaxed during lock-down. This finding requires further investigation to understand the factors that make students relaxed during lock-down.

The current study did not use any standardized instrument to measure students' wellbeing or affect. Though it is not appropriate to compare the results of the current study with earlier researches that used different instruments, the comparison has been done to understand the findings of the current study in the light of related literature. Prior literature shows that positive affect among the elementary school students was higher than older students (Greene, 1990). In the current study, mean scores are highest (mathematically) for 10-12 year old children and lowest for the 16-18 year old children. However, ANOVA results 
show that these scores were not statistically different. Further research, with more number of students, is required to see if age is a predictor of 10-18 year old students' affect during lockdown

The current study found a difference in the mean scores on the basis of gender. Mean score of boys was higher as compared to girls on the 9 items of 'Lock-down Affect Scale'. These findings are in line with the earlier researches (Burns \& Machin, 2013; Garcia, 2011) that used different instruments to measure the affect. Burns and Machin (2013) found that females scored higher on negative affect. Similar results were found in the studies that included adolescents. For example, Garcia (2011) and Jaques and Mash (2004) noticed a higher negative affect among girls.

Literature (Burns \& Machin 2010; Kling et al., 2003) shows that personality is a predictor of well-being and affect. The people who are more open to any experiences show more 'positive affect' (Headey and Wearing, 1989). In the current study, students' personality was not measured. However, one trait of personality i.e. self-regulation or independent learning was identified. Hofmann, Schmeichel and Baddeley (2012) see flexibility or openness as a key aspect of self-regulation. The study findings, related to selfregulation, support the argument that openness and positive affect have a relationship (Kling et al., 2003). The study found that the $94 \%$ of the self-reported independent/ self-regulatory learners took lock-down as an opportunity to do something differently. The study also found that the mean scores of the self-reported independent learners were higher on the 'Lock-down Affect Scale' as compared to the means scores of 'self-reported Not Independent learners'. This finding suggests that the educational institutes should provide opportunities to the children to develop them as self-regulatory learners.

The study findings may be explained in the light of literature on self-regulatory learning too. The current study indicates that self-regulation is a predictor of well-being/ 
affect. Earlier research has shown that poor self-regulation is a predictor of future problems in school (Ponitz et al., 2008). The underlying reason could be the 'negative affect' related to poor self-regulation. This requires further investigation. Pintrich et al. (1993) argues that selfregulated learners are persistent, motivated and manage their time effectively. The findings of the current study also show that the self-reported independent learners were more persistently involved in some actions or activities and managed their time of lock-down. It is also important to note that more than $20 \%$ of the self-reported independent learners claimed that the lock-down had made them independent learners as they had started learning things from online sources. This indicates that the use of online platform helps students become more independent. This is in line with the findings of Broadbent (2017) who found a relationship between online learning and self-regulatory learning. However, this claim requires further investigation.

Independent learning/ self-regulatory learning has emerged as an important predictor of well-being/ affect in the current study. Bronson (2000) also found that self-regulation affects the emotional developments of children. These findings suggest that the schools should provide opportunities to the students to make them self-regulatory learners. These opportunities can be provided through different processes like 'self-assessment' (Black \& Wiliam,1998), making choices, and taking decisions (Whitebread et al., 2005).

The study findings related to the activities and actions the students are involved in (Table 5) indicate that the students of age 10-18 in Pakistan have only a few activities to engage in. Only four students $(2 \%)$ mentioned that they were involved in writing activities. Physical exercise was mentioned only by one student. Art work was mentioned by $4 \%$. These findings suggest that children should be exposed to more activities and skills so that they can keep themselves engaged during some unpredictable and sudden situations. 


\section{Conclusions}

The study findings lead to some important conclusions regarding educational services in Pakistan. The study also draws conclusions regarding the predictors of well-being/ affect in the 10-18 year-old students. A significantly lower mean score on the 'Lock-down Affect Scale' indicate that the 10-18 year-old students in Pakistan are not psychologically equipped to face the situation of emergencies. The study suggests that disaster and risk management should be included as compulsory elements in the school curricula. The findings indicate a relationship between self-regulation and well-being during Covid-19. The findings suggest a revision in school curricula and teaching approaches to engage children in activities that can make them self-regulatory learners. Students should be taught some skills like instrument playing, stitching, gardening, or farming. In addition, the study findings have raised questions about the management of educational services in emergencies.

\section{References}

Badri, A., Eltayeb, S., Mohamed, M., \& Verdeli, H. (2020). Mental Health and Resilience Status Of Eritrean Unaccompanied Refugee Minors In Sudan. Children and Youth Services Review.

Balaban, V. (2006). Psychological assessment of children in disasters and emergencies. Disasters, 30(2), 178-198.

Bandura, A. (2001). Social cognitive theory: An agentic perspective. Annual review of psychology, 52(1), 1-26.

Betancourt, T. S., \& Khan, K. T. (2008). The mental health of children affected by armed conflict: Protective processes and pathways to resilience. International review of psychiatry, 20(3), 317-328.

Black, P., \& Wiliam, D. (1998). Assessment and classroom learning. Assessment in Education: principles, policy \& practice, 5(1), 7-74.

Broadbent, J. (2017). Comparing online and blended learner's self-regulated learning strategies and academic performance. The Internet and Higher Education, 33, 24-32.

Broadbent, J., \& Poon, W. L. (2015). Self-regulated learning strategies \& academic achievement in online higher education learning environments: A systematic review. The Internet and Higher Education, 27, 1-13. 
Burke, J. D., Hipwell, A. E., \& Loeber, R. (2010). Dimensions of oppositional defiant disorder as predictors of depression and conduct disorder in preadolescent girls. Journal of the American Academy of Child \& Adolescent Psychiatry, 49(5), 484-492.

Burns, R. A., \& Machin, M. A. (2010). Identifying gender differences in the independent effects of personality and psychological well-being on two broad affect components of subjective well-being. Personality and Individual Differences, 48(1), 22-27.

Cardak, M. (2013). Psychological well-being and Internet addiction among university students. Turkish Online Journal of Educational Technology-TOJET, 12(3), 134-141.

Chang, L., McBride-Chang, C., Stewart, S. M., \& Au, E. (2003). Life satisfaction, selfconcept, and family relations in Chinese adolescents and children. International Journal of Behavioral Development, 27(2), 182-189.

Cross, D. R., \& Paris, S. G. (1988). Developmental and instructional analyses of children's metacognition and reading comprehension. Journal of educational psychology, 80(2), 131.

DeFosset, A. R., Schooley, T. S., Abrams, L. S., Kuo, T., \& Gase, L. N. (2017). Describing theoretical underpinnings in juvenile justice diversion: A case study explicating Teen Court program theory to guide research and practice. Children and Youth Services Review, 73, 419429.

Dettori, G., \& Persico, D. (Eds.). (2010). Fostering self-regulated learning through ICT. IGI global.

Downer, R. T. (2013). Homelessness and its consequences: The impact on children's psychological well-being. Routledge.

Ebesutani, C., Regan, J., Smith, A., Reise, S., Higa-McMillan, C., \& Chorpita, B. F. (2012). The 10-item positive and negative affect schedule for children, child and parent shortened versions: application of item response theory for more efficient assessment. Journal of Psychopathology and behavioral Assessment, 34(2), 191-203.

Ehrman, M. E., Leaver, B. L., \& Oxford, R. L. (2003). A brief overview of individual differences in second language learning. System, 31(3), 313-330.

Elfenbein, H. A. (2007). 7 Emotion in organizations: a review and theoretical integration. Academy of management annals, 1(1), 315-386.

Fogle, L. M., Huebner, E. S., \& Laughlin, J. E. (2002). The relationship between temperament and life satisfaction in early adolescence: Cognitive and behavioral mediation models. Journal of Happiness Studies, 3(4), 373-392.

Garcia, D. (2011). Two models of personality and well-being among adolescents. Personality and Individual Differences, 50(8), 1208-1212.

Garcia, D. (2011). Two models of personality and well-being among adolescents. Personality and Individual Differences, 50(8), 1208-1212. 
Giannini, S. (2020). Prioritize health and well-being now and when schools reopen.

Greene, A. L. (1990). Patterns of affectivity in the transition to adolescence. Journal of Experimental Child Psychology, 50(3), 340-356.

Headey, B., \& Wearing, A. (1989). Personality, life events, and subjective well-being: toward a dynamic equilibrium model. Journal of Personality and Social psychology, 57(4), 731.

Hofmann, W., Schmeichel, B. J., \& Baddeley, A. D. (2012). Executive functions and selfregulation. Trends in cognitive sciences, 16(3), 174-180.

Holman, B., \& Ziedenberg, J. (2006). The dangers of detention. Washington, DC: Justice Policy Institute.

https://en.unesco.org/news/prioritize-health-and-well-being-now-and-when-schools-reopen

Huebner, E. S., \& Dew, T. (1995). Preliminary validation of the positive and negative affect schedule with adolescents. Journal of Psychoeducational Assessment, 13(3), 286-293.

Jacques, H. A. K., \& Mash, E. J. (2004). A test of the tripartite model of anxiety and depression in elementary and high school boys and girls. Journal of Abnormal Child Psychology, 32, 13-25

Jacques, H. A. K., \& Mash, E. J. (2004). A test of the tripartite model of anxiety and depression in elementary and high school boys and girls. Journal of Abnormal Child Psychology, 32, 13-25.

Kapasia, N., Paul, P., Roy, A., Saha, J., Zaveri, A., Mallick, R., ... \& Chouhan, P. (2020). Impact of lock-down on learning status of undergraduate and postgraduate students during COVID-19 pandemic in West Bengal, India. Children and Youth Services Review, 105194.

Kling, K. C., Ryff, C. D., Love, G., \& Essex, M. (2003). Exploring the influence of personality on depressive symptoms and self-esteem across a significant life transition. Journal of personality and social psychology, 85(5), 922.

Lai, E. R. (2011). Metacognition: A literature review. Always learning: Pearson research report, 24.

http://images.pearsonassessments.com/images/tmrs/metacognition_literature_review_final.pd $\underline{\mathrm{f}}$

Laurent, J., Catanzaro, S. J., Joiner Jr, T. E., Rudolph, K. D., Potter, K. I., Lambert, S., ... \& Gathright, T. (1999). A measure of positive and negative affect for children: scale development and preliminary validation. Psychological assessment, 11(3), 326.

learning. Learning and Skills Research, 6(1), 3.

Lee, J. (2020). Mental health effects of school closures during COVID-19. The Lancet Child \& Adolescent Health, 4(6), 421. 
Lee, S. J., \& Ward, K. P. (2020). Parents are having more conflict with children since pandemic. Available from: https://news.umich.edu/coronavirus-causing-conflict-betweenparents-children/ Accessed May 31, 2020.

Lyubomirsky, S., \& Ross, L. (1999). Changes in attractiveness of elected, rejected, and precluded alternatives: A comparison of happy and unhappy individuals. Journal of personality and social psychology, 76(6), 988.

Lyubomirsky, S., Sheldon, K. M., \& Schkade, D. (2005). Pursuing happiness: The architecture of sustainable change. Review of general psychology, 9(2), 111-131.

MacBeath, J. (1993). Learning for Yourself: Supported Study in Strathclyde Schools.

Machel, G. (2001). The Impact of War on Children: A Review of Progress Since the 1996 United Nations Report on the Impact of Armed Conflict on Children. United Nations Children's Fund.

Mazzucato, V., Cebotari, V., Veale, A., White, A., Grassi, M., \& Vivet, J. (2015). International parental migration and the psychological well-being of children in Ghana, Nigeria, and Angola. Social Science \& Medicine, 132, 215-224.

McFarlane, C. A., Kaplan, I., \& Lawrence, J. A. (2011). Psychosocial indicators of wellbeing for resettled refugee children and youth: Conceptual and developmental directions. Child Indicators Research, 4(4), 647-677.

Meyer, W. R. (2010, September). Independent learning: a literature review and a new project. In British Educational Research Association Annual Conference (Vol. 35). http://www.leeds.ac.uk/educol/documents/193305.pdf

Ornelas, I. J., \& Perreira, K. M. (2011). The role of migration in the development of depressive symptoms among Latino immigrant parents in the USA. Social science \& medicine, 73(8), 1169-1177.

Pintrich, P. R., Smith, D. A., Garcia, T., \& McKeachie, W. J. (1993). Reliability and predictive validity of the Motivated Strategies for Learning Questionnaire (MSLQ). Educational and psychological measurement, 53(3), 801-813.

Pollard, E. L., \& Lee, P. D. (2003). Child well-being: A systematic review of the literature. Social Indicators Research, 61(1), 59-78.

Pollard, E. L., \& Lee, P. D. (2003). Child well-being: A systematic review of the literature. Social indicators research, 61(1), 59-78.

Ponitz, C. C., McClelland, M. M., Jewkes, A. M., Connor, C. M., Farris, C. L., \& Morrison, F. J. (2008). Touch your toes! Developing a direct measure of behavioral regulation in early childhood. Early Childhood Research Quarterly, 23, 141-158

Roje Đapić, M., Buljan Flander, G., \& Prijatelj, K. (2020). Children Behind Closed Doors Due to COVID-19 Isolation: Abuse, Neglect and Domestic Violence. Archives of Psychiatry Research: An International Journal of Psychiatry and Related Sciences, 56(2), 181-192. 
Schraw, G. (1998). On the development of adult metacognition. Adult learning and development: Perspectives from educational psychology, 89-106.

Singh, K., \& Jha, S. D. (2008). Positive and negative affect, and grit as predictors of happiness and life satisfaction. Journal of the Indian Academy of Applied Psychology, 34(2), 40-45.

Singh, K., \& Jha, S. D. (2008). Positive and negative affect, and grit as predictors of happiness and life satisfaction. Journal of the Indian Academy of Applied Psychology, 34(2), 40-45.

Tiwari, G. K., Singh, A. K., Parihar, P., Pandey, R., Sharma, D. N., \& Rai, P. K. (2020). Understanding the perceived health outcomes of children during COVID-19 pandemic. Available at: https://www.researchgate.net/profile/Gyanesh_Tiwari/publication/341417291_Understanding the_perceived_health_outcomes_of_children_during_COVID19 pandemic/links/5ebf823f92851c11a86c3dc2/Understanding-the-perceived-healthoutcomes-of-children-during-COVID-19-pandemic.pdf [Accessed May 25, 2020].

UNESCO (2020 a). Global Education Coalition. https://en.unesco.org/covid19/educationresponse/globalcoalition [Accessed May 30, 2020].

UNESCO (2020 b). Adverse consequences of school closures. https://en.unesco.org/covid19/educationresponse/consequences [Accessed May 30, 2020].

UNICEF (2020). Videos. https://www.unicef.org/coronavirus/kids-video-diaries-about-lifeduring-covid-19 [Accessed May 31, 2020].

UNICEF. COVID-19: Children at heightened risk of abuse, neglect, exploitation and violence amidst intensifying containment measures [Internet] 2020. Available from: https:// www.unicef.org/press-releases/covid-19-childrenheightened-risk-abuse-neglect-exploitationandviolence-amidst [Accessed May 31, 2020].

van der Laan, A., \& Eichelsheim, V. (2013). Juvenile adaptation to imprisonment: Feelings of safety, autonomy and well-being, and behaviour in prison. European Journal of Criminology, 10(4), 424-443.

van Knippenberg, D., Kooij-de Bode, H. J., \& van Ginkel, W. P. (2010). The interactive effects of mood and trait negative affect in group decision making. Organization Science, 21(3), 731-744.

Veronese, G., Pepe, A., Jaradah, A., Al Muranak, F., \& Hamdouna, H. (2017). Modelling life satisfaction and adjustment to trauma in children exposed to ongoing military violence: An exploratory study in Palestine. Child abuse \& neglect, 63, 61-72.

Watson, D., Clark, L. A., \& Tellegen, A. (1988). Development and validation of brief measures of positive and negative affect: The PANAS scales. Journal of Personality and Social Psychology, 54, 1063-1070. 
Whitebread, D., Anderson, H., Coltman, P., Page, C., Pasternak, D. P., \& Mehta, S. (2005). Developing independent learning in the early years. Education 3-13, 33(1), 40-50.

Whitebread, D., Coltman, P., Pasternak, D. P., Sangster, C., Grau, V., Bingham, S., ... \& Demetriou, D. (2009). The development of two observational tools for assessing metacognition and self-regulated learning in young children. Metacognition and learning, 4(1), 63-85.

Zimmerman, B. J. (1995). Self-regulation involves more than metacognition: A social cognitive perspective. Educational psychologist, 30(4), 217-221. 